\title{
Experience in the use of tolvaptan in elderly patients with significant hyponatraemia
}

\author{
Agnieszka Swiecicka, Rahul Nayar, Ashwin Joshi \\ Department of Endocrinology, Diabetes and Metabolic Medicine; City hospitals Sunderland NHS \\ Foundation Trust, Sunderland, UK
}

\section{INTRODUCTION:}

Tolvaptan is an oral vasopressin $V_{2}$ receptor antagonist which offers a novel treatment for euvolaemic and hypervolaemic hyponatraemia. Here we report our experience with Tolvaptan in elderly patients.

\section{Case 1:}

76-year-old lady with background of hypothyroidism, hypertension and alcohol excess presented with acute onset of confusion. Her admission Sodium $\left[\mathrm{Na}^{+}\right]$level was $117 \mathrm{mmol} / \mathrm{L}$ and represented an acute drop from normal level after a thiazide diuretic was introduced two days earlier. Acute thyroid dysfunction and adrenal insufficiency were excluded. Despite stopping bendroflumethiazide, $\left[\mathrm{Na}^{+}\right]$fell further to $108 \mathrm{mmol} / \mathrm{L} 48 \mathrm{hrs}$ later. Urinary spot $\left[\mathrm{Na}^{+}\right]$was $29 \mathrm{mmol} / \mathrm{L}$ and urine osmolality $766 \mathrm{mOsm} / \mathrm{kg}$ in the context of euvolaemia. Following administration of $15 \mathrm{mg}$ of Tolvaptan, $\left[\mathrm{Na}^{+}\right]$level rose to $117 \mathrm{mmol} / \mathrm{L}$ on day one and $122 \mathrm{mmol} / \mathrm{L}$ on day two. Tolvaptan was discontinued and hyponatraemia improved on fluid restriction only with $\left[\mathrm{Na}^{+}\right]$level $132 \mathrm{mml} / \mathrm{L} 48$ hours later.

\section{Case 2:}

91-year-old lady with known congestive cardiac failure and hypertension was admitted with a fall. She was known to have mild hyponatraemia, secondary to loop diuretic use. $\left[\mathrm{Na}^{+}\right]$level fell rapidly from $130 \mathrm{mmol} / \mathrm{L}$ to $115 \mathrm{mmol} / \mathrm{L}$ a week post admission and continued to decline despite withholding the diuretic and ACEi, fluid restriction and Demeclocycline use (300 mg 6 hourly). Plasma osmolality was low at $245 \mathrm{mOsm} / \mathrm{kg}$ with urine osmolality at $598 \mathrm{mOsm} / \mathrm{kg}$. Thyroid dysfunction and hypocortisolaemia were excluded. Tolvaptan $15 \mathrm{mg}$ was introduced at $\left[\mathrm{Na}^{+}\right]$level of $106 \mathrm{mmol} / \mathrm{L}$ and resulted in gradual improvement in hyponatraemia with $\left[\mathrm{Na}^{+}\right]$level at $111 \mathrm{mmol} / \mathrm{L}$ on day $1,118 \mathrm{mmol} / \mathrm{L}$ on day 2 and 127 $\mathrm{mmo} / \mathrm{L}$ on day 3 post Tolvaptan. The medication $\mathrm{w}$ as discontinued and $\left[\mathrm{Na}^{+}\right]$level remained stable on fluid restriction.

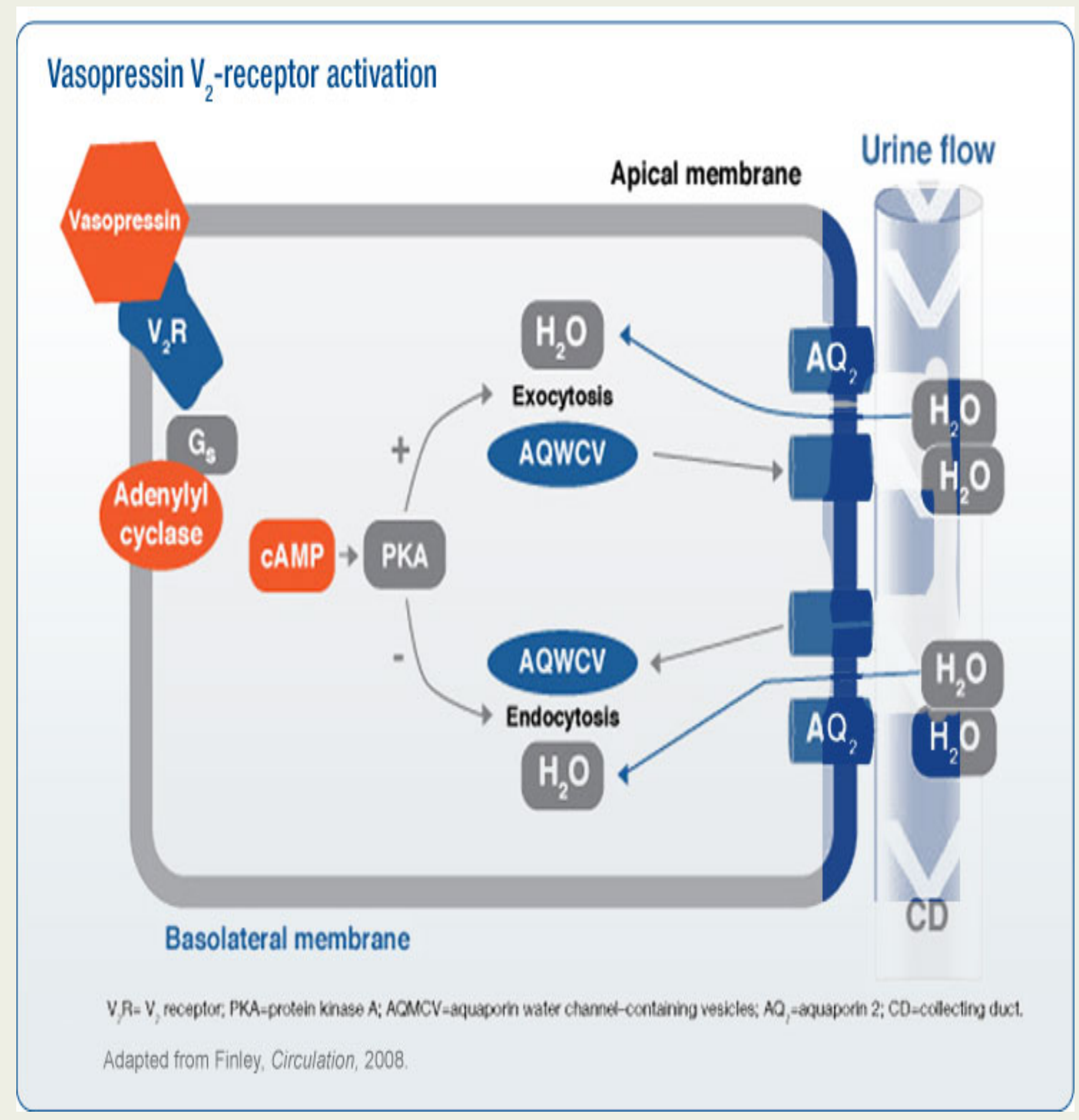

\section{CONCLUSION:}

Tolvaptan is a safe and effective treatment of hyponatraemia in elderly population providing more prompt rise in serum sodium than fluid restriction and Demeclocycline. 